\title{
Application of Artificial Ground Freezing Technology in Modern Urban Underground Engineering
}

\author{
Yi Qi $\complement^{\circ}$, Jinxun Zhang, Hao Yang, and Yongwei Song \\ Postdoctoral Workstation, Beijing Urban Construction Group Co., Ltd., Beijing 100088, China \\ Correspondence should be addressed to Yi Qi; qiyi@mail.bucg.com
}

Received 12 June 2020; Accepted 21 July 2020; Published 7 August 2020

Academic Editor: Francisco Javier Fernández Fernández

Copyright ( 92020 Yi Qi et al. This is an open access article distributed under the Creative Commons Attribution License, which permits unrestricted use, distribution, and reproduction in any medium, provided the original work is properly cited.

\begin{abstract}
Based on typical water-rich sandy gravel strata in Beijing, in order to explore the application of the artificial ground freezing method (AGF) in urban large-scale underground engineering, the formation and development of freezing body were analyzed when multirow freezing pipes were working together, and the group effect exhibited during the freezing process was also revealed in this paper. On this basis, the basin-shaped freezing method (BFM) is put forward as an application of AGF used in underground engineering. BFM structure consists of two parts: the frozen curtain (basin wall) around the excavation scope and the horizontal frozen body (basin bottom) at the bottom of the station. Physical model test and numerical simulation were conducted to study temperature field expansion of BFM under two different conditions. The results show the following: (1) The group effect refers to the cooling effect of different freezing pipes influencing each other during freezing process. Under the condition of still water, the group effect expands the freezing area, and it shows the gradual development of freezing from back water surface to front water surface under seepage condition. (2) BFM can effectively play the role of water proofing, and although different parts of basin structure show different frozen order under different conditions, both basin wall and basin bottom can form an effective thickness during the freezing process.
\end{abstract}

\section{Introduction}

Artificial ground freezing technology (AGF) uses the refrigeration system to turn natural soil frozen, increase its strength, and isolate groundwater. First applied in mining engineering, AGF was introduced into municipal engineering because of its flexible, controllable, and environment-friendly characteristics [1].

In the 1970s, AGF was first applied to a subway in China with a freezing length of $90 \mathrm{~m}$, and, after that, it has been successfully used for bypass of many subway lines in Shanghai and Beijing since 1993 [2]. In 1997, the first horizontal AGF tunnel was carried out in Beijing [3]. In 2003, Guangzhou Metro Line 2 passed through a fractured zone, and AGF was used to strengthen the unstable stratum [4]. In recent years, AGF has become one of the main methods for underground engineering in soft water-bearing strata to build bypass, deal with accidents, and strengthen strata.
According to engineering requirements, experts and scholars have proposed different freezing pipes layout and studied their temperature field expansion, respectively. Among them, Yang and $\mathrm{Pi}[5]$ established a mathematical model of a single freezing pipe and studied the influence of parameters on its limit value; Zhou [6,7] studied the closure time and temperature field of freezing pipes around the wellbore under seepage condition by numerical simulation and model test; Gao et al. [8] established the numerical model of double freezing pipes in fractured rock under the seepage flow and analyzed the influence of fracture on temperature field and seepage field; Li et al. [9] established a test system of double-row freezing pipes with quincunx arrangement under seepage condition, and the main factors of the frozen wall were studied by orthogonal test; Liu et al. [10] studied the frozen wall formation under horizontal flow with the pipes in rectangular layout and compared frozen thickness and closure time at upstream and downstream frozen wall. At present, the freezing scope of these projects is 
quite limited, and there is no case of applying AGF to largescale underground projects.

Nowadays, China is continuously strengthening groundwater protection. As a pilot city for water resources reform [11], Beijing has imposed heavy taxes on the pumping of groundwater for construction projects. As a result, it has become very important to carry out research on no pumping (or less pumping) for large-scale underground engineering, and now AGF is believed to effectively solve the problem.

In this paper, based on the typical water-rich sandy gravel strata in Beijing, in order to solve the difficulty of large-scale underground engineering water proofing in urban sensitive areas, the formation and development of freezing body were analyzed when multirow freezing pipes were working together, and the group effect exhibited was also revealed. On this basis, the basin-shaped freezing method (BFM) is put forward as an application of AGF used in large-scale underground engineering; temperature field expansion of this method is carefully studied, especially freezing sequence of different positions of basin structure under different seepage conditions. It provides a basis for the application of BFM in underground engineering and has certain engineering significance.

\section{Basin-Shaped Freezing Method}

In traditional mine shaft construction, freezing pipes were arranged vertically around the wall to form a ring-shaped frozen wall to resist water and soil pressure, so, as for the bypass, the freezing pipes with nearly horizontal inclination are used to isolate groundwater between the two tunnels and form a frozen zone for construction. But, for large-scale underground engineering, these freezing methods are no longer applicable.

In order to explore the application of AGF in urban large-scale underground engineering, more freezing pipes are needed. When multiple rows of freezing pipes are working as a group, a horizontal frozen body can be formed as shown in Figure 1.

For large-scale underground engineering in sensitive areas of urban cities, not only the bottom but also around the excavation area is supposed to be isolated groundwater. On this basis, the basin-shaped freezing method (BFM) is put forward as an application of AGF used in underground engineering. BFM consists of two parts, the basin wall and the basin bottom. The basin wall is located around the excavation area, forming a closed circular freezing curtain by arranging vertical freezing pipes, while the basin bottom is regularly arranged with multirow freezing pipes below the excavation area; part-freezing method was adapted to form a horizontal freezing plate connecting with the basin wall, which is shown in Figure 2.

BFM is suitable for large-scale projects with a certain depth in the excavated area and no effective water barrier. The basin wall and basin bottom jointly resist the hydraulic connection to form a water proof interval and finally ensure the smooth progress of the project.

\section{Group Effect of Multirow Pipes Freezing}

The artificial freezing process is affected by environmental factors, and the freezing process will also change those factors and have an impact conversely, so the freezing development eventually shows a double nonlinear relationship. In addition, the flow of groundwater will drive the migration of cool water, making the multirow pipe freezing problem more complicated. Numerical simulation is used to analyze the group-effect in the case of multirow pipe freezing.

3.1. Numerical Implementation Method. AGF is a multifield coupling problem involving temperature field and seepage field. This practical problem includes physical processes such as phase transition and moving boundary. Equations (1) and (2) are followed during the process [12]. Due to the complexity of the problem, the following assumptions are made in the numerical simulation process:

(1) Soil is a homogeneous, continuous, and isotropic saturated porous medium, and the pores are interconnected with each other; in the process of seepage, the microprocess of groundwater flowing in the soil void is not considered, but the average seepage velocity of the section is only concerned.

(2) Assuming that the ice-water phase transition only occurs in the interval $[-1,0]$, the latent heat capacity method is used to treat the heat released by freezing water into ice, during the latent heat capacity of the phase transformation process, ignoring the migration of unfrozen water in the freezing process.

(3) The permeability coefficient in porous media is considered as a function of temperature. When the temperature is lower than $0^{\circ} \mathrm{C}$, the permeability coefficient decreases to about 0 to simulate the freezing process of water to ice:

$$
\begin{gathered}
K_{e f} \nabla^{2} T+\left[-\rho_{L} C_{L} \mathbf{u} \cdot \nabla T\right]+Q=\rho_{L} L \frac{\partial \theta}{\partial t}+C_{e f} \frac{\partial T}{\partial t}, \\
\frac{\partial \mathbf{u}}{\partial t}+(\mathbf{u} \cdot \nabla) \mathbf{u}=\mathbf{f}-\frac{1}{\rho} \nabla p+\gamma \nabla^{2} \mathbf{u},
\end{gathered}
$$

where $\rho_{L}$ is the density of water; $\mathbf{u}$ is the velocity field vector of fluid seepage; $C_{L}$ is the specific heat capacity of water; $Q$ is the system heat source; $L$ is the latent heat value released when the unit mass of water changes phase; $\theta_{L}$ is the content of liquid water; $t$ is the time; $\mathbf{f}$ is the mass force received by the fluid unit; $\gamma$ is the gravity of water.

In the process of artificial freezing, the heat capacity of porous media can be expressed by the volume weighted average value of heat capacity of mixture, namely, the equivalent heat capacity $C_{e f}$. Similarly, the thermal conductivity of porous media can also be expressed as the equivalent thermal conductivity $K_{e f}$ of soil skeleton-waterice mixture, which can be calculated by the following equations, respectively: 


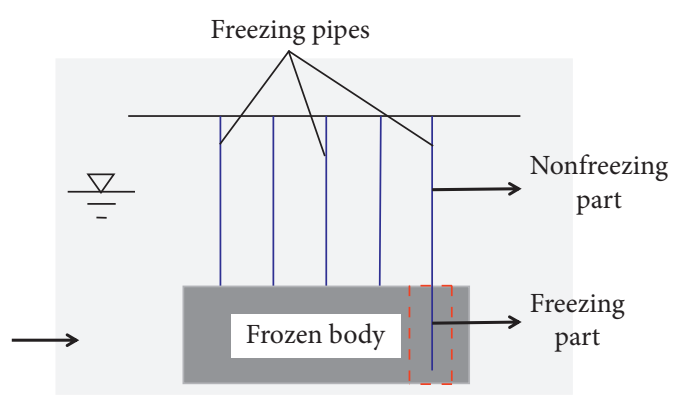

(a)

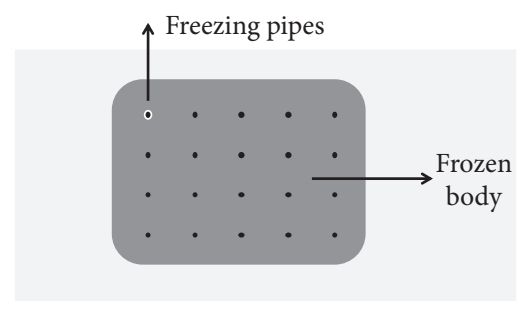

(b)

Figure 1: Horizontal frozen body forming by multiple rows of freezing pipes. (a) Cross section. (b) Plane figure.

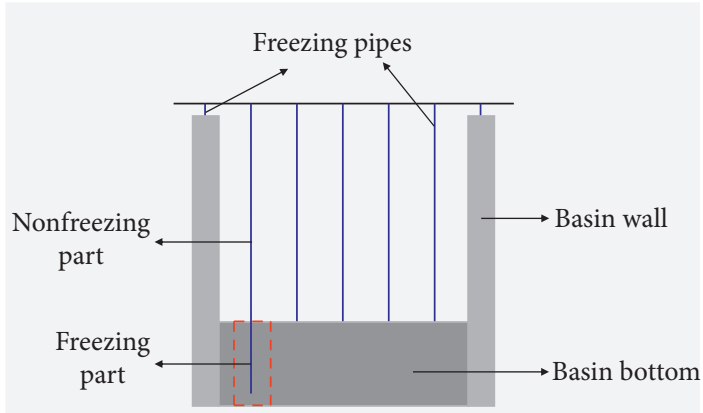

(a)

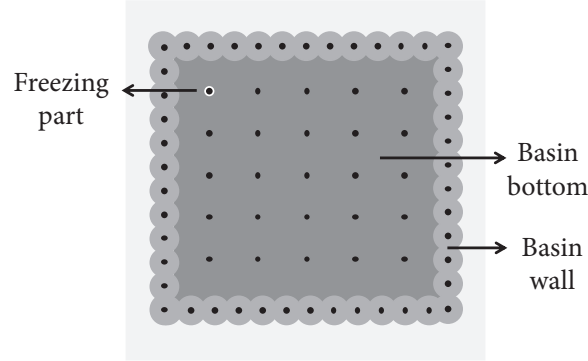

(b)

Figure 2: Basin-shaped freezing technology. (a) Cross section. (b) Plane figure.

$$
\begin{aligned}
& C_{e f}=\varphi \theta_{L} \rho_{L} C_{L}+\varphi\left(1-\theta_{L}\right) \rho_{I} C_{I}+\left(1-\theta_{L}\right) \rho_{S} C_{S}+\rho_{L} L \frac{\partial \theta_{L}}{\partial t}, \\
& K_{e f}=\varphi \theta_{L} K_{L}+\varphi\left(1-\theta_{L}\right) K_{I}+(1-\varphi) K_{S},
\end{aligned}
$$

where $\varphi$ is the porosity of porous media; $\rho_{s}$ is the density of soil skeleton; $\rho_{I}$ is the density of ice; $C_{S}$ is the specific heat capacity of soil skeleton; $C_{I}$ is the specific heat capacity of ice; $K_{L}$ is the heat conduction of water.

During the freezing process, (1) is a heat transfer equation including phase change, which is used to solve temperature $T$, while (2) is an N-S equation of momentum conservation of incompressible fluid, which is used to solve pressure $p$ and velocity $\mathbf{u}$ in freezing process. Parameters involved in the test process are shown in Table 1.

\subsection{Group Effect under Still Water. COMSOL Multiphysics} was used to establish the multirow freezing pipes model when their spacing is $2 \mathrm{~m}$, as shown in Figure 3. During the freezing process, the freezing column radius of one pipe among the group is recorded and compared with that of a single freezing pipe under the same conditions, as shown in Figure 4.

It can be seen from Figure 4 that, during the freezing process of a single pipe, the radius of its freezing column gradually stabilized at a fixed value after the initial rapid development. The radius of the freezing column is $0.45 \mathrm{~m}$ in the end under this working condition. For one pipe in group, in the initial stage of freezing, the distance between the columns of frozen soil is large, so the mutual influence is limited, and so the freezing process is very similar to that of a single pipe at this stage. Subsequently, the radius is expanding, which reduces ambient temperature and promotes the development of freezing. After that, the freezing column radius expanded rapidly, and finally the adjacent frozen soil columns were connected.

By comparison, it is found that, under still water, the freezing column radius of a single pipe is much smaller than that of one pipe in group when the freezing development is stable, and the latter is equal to half the spacing. The difference between them is that, for one pipe in group, the freezing process will be strengthened by the superposition of the cooling effect of the surrounding freezing pipes. Therefore, under the condition of still water, the group-effect is manifested by the expansion of each pipe freezing column radius and acceleration of the overall freezing process.

3.3. Group Effect under Seepage Condition. A 10-row freezing pipes array with a spacing of $2.0 \mathrm{~m}$ was established, and the freezing process became stable after 40-day simulation under seepage conditions $(0.5 \mathrm{~m} / \mathrm{d})$. In the end, the pipes group froze as a whole, and the temperature field distribution at each stage is shown in Figure 5.

During the first 8 days, the freezing trend is almost parallel to the direction of the water flow, and the freezing 
TABle 1: Parameters of the model.

\begin{tabular}{lccc}
\hline Physical quantities & Symbol & Value & Unit \\
\hline Water density & $\rho_{L}$ & 1000 & $\mathrm{~kg} / \mathrm{m}^{3}$ \\
Ice density & $\rho_{I}$ & 800 & $\mathrm{~kg} / \mathrm{m}^{3}$ \\
Sandy gravel density & $\rho_{S}$ & 2500 & $\mathrm{~kg} / \mathrm{m}^{3}$ \\
Water specific heat & $C_{L}$ & 4182 & $\mathrm{~J} /\left(\mathrm{kg}^{*} \mathrm{~K}\right)$ \\
Ice specific heat & $C_{I}$ & 2091 & $\mathrm{~J} /\left(\mathrm{kg}^{*} \mathrm{~K}\right)$ \\
Sandy gravel specific heat & $C_{S}$ & 780 & $\mathrm{~J} /\left(\mathrm{kg}^{*} \mathrm{~K}\right)$ \\
Water thermal conductivity & $K_{L}$ & 0.6 & $\mathrm{~W} /\left(\mathrm{m}^{*} \mathrm{~K}\right)$ \\
Ice thermal conductivity & $K_{I}$ & 2.2 & $\mathrm{~W} /\left(\mathrm{m}^{*} \mathrm{~K}\right)$ \\
Sandy gravel thermal conductivity & $K_{S}$ & 2.3 & $\mathrm{~W} /\left(\mathrm{m}^{*} \mathrm{~K}\right)$ \\
Latent heat of water & $L$ & 333 & $\mathrm{~kJ} / \mathrm{kg}$ \\
Porosity of sandy gravel & $\varphi$ & 18.5 & $\%$ \\
Permeability coefficient & $k_{u}$ & 11.1 & $\mathrm{~m} / \mathrm{d}$ \\
\hline
\end{tabular}
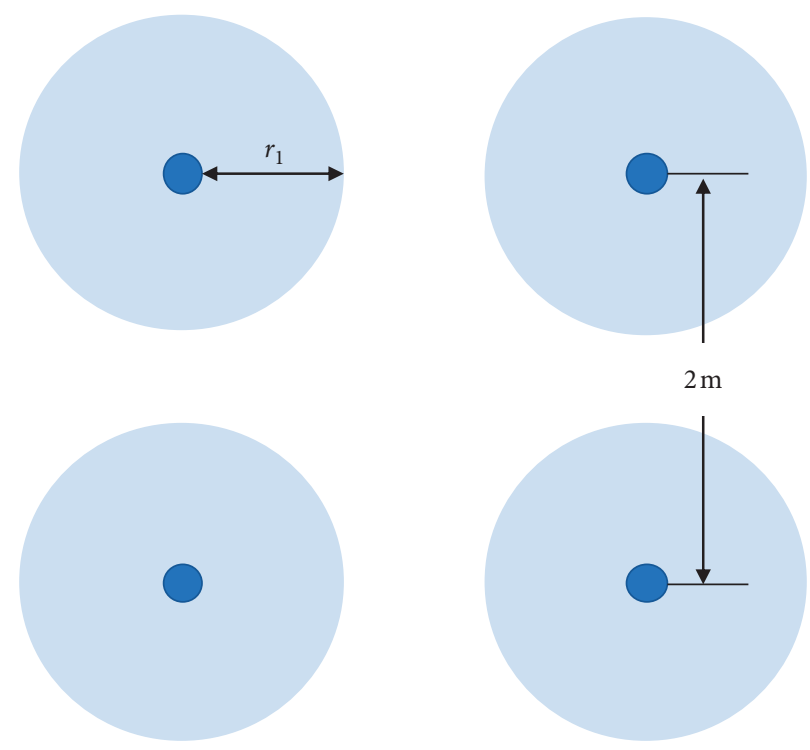

Figure 3: Multirow freezing pipes.

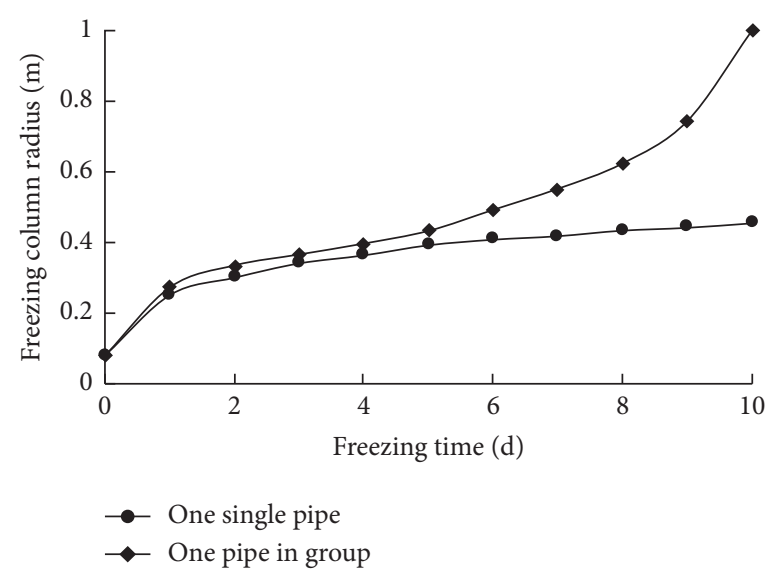

Figure 4: Comparison of freezing surface radius.

soil column gradually connected, which increases along the flow, as shown in Figure 6. It can be considered that the freezing column around each pipe is the superposition of the cooling effect of all the pipes upstream of it. According to the frozen form, under seepage conditions, the cooling capacity of each freezing pipe is transmitted outward at an angle.

With the development of freezing, the cooling capacity diffusion ranges of two adjacent pipes in a row will overlap 


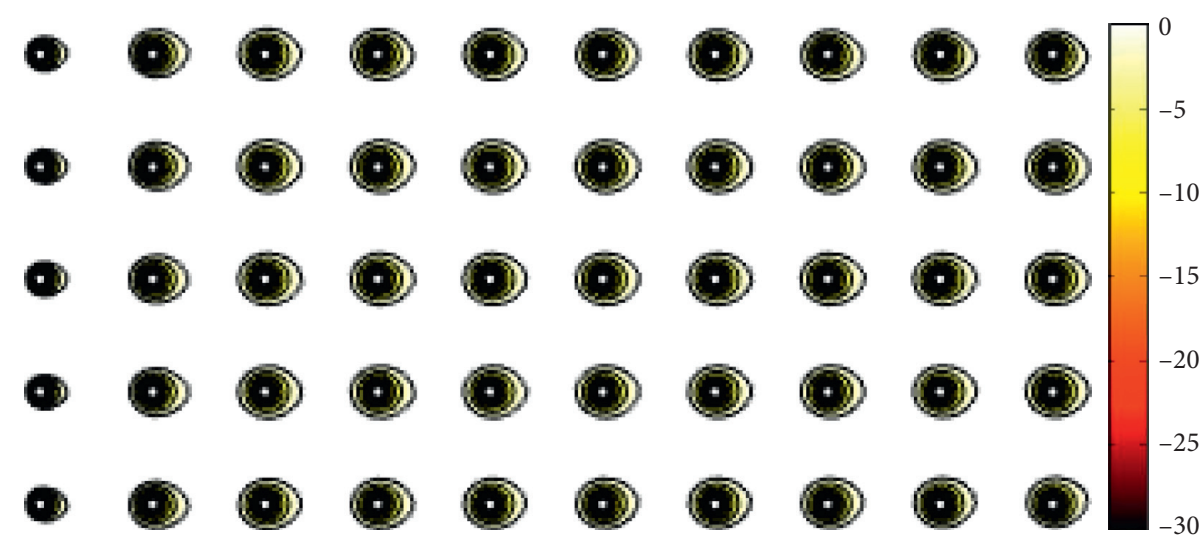

(a)

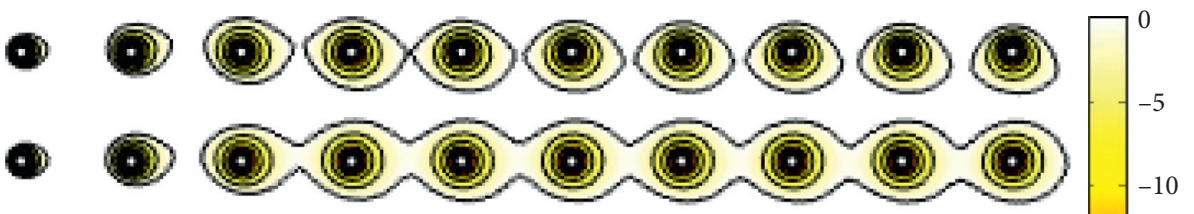

- (9)(9)(9)(9)(9)(9) (9) ${ }^{-15}$

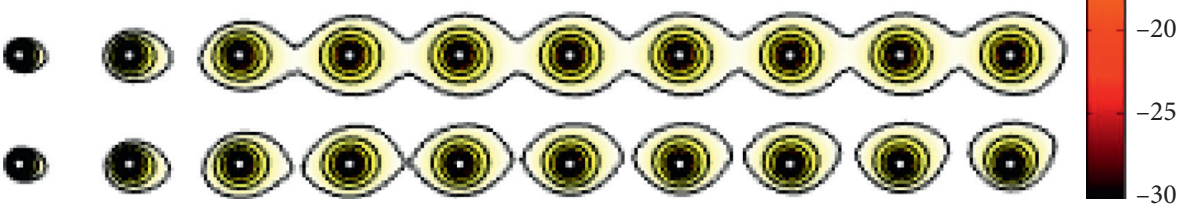

(b)

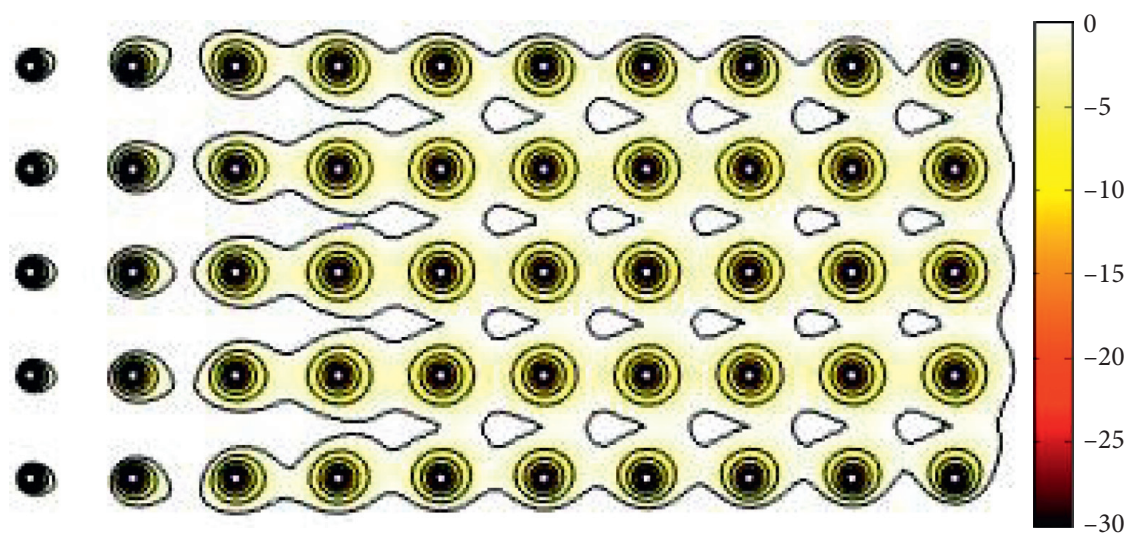

(c)

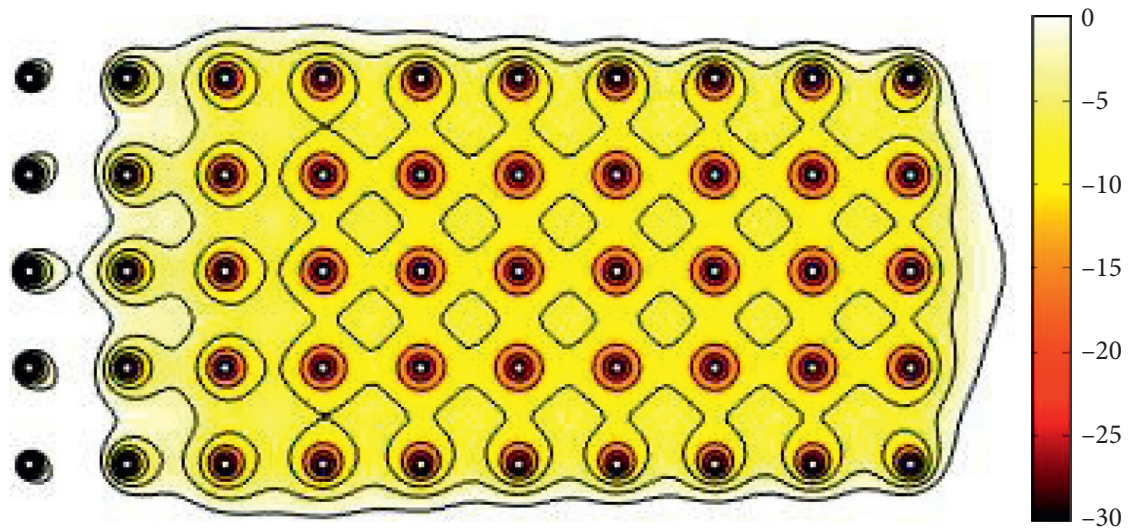




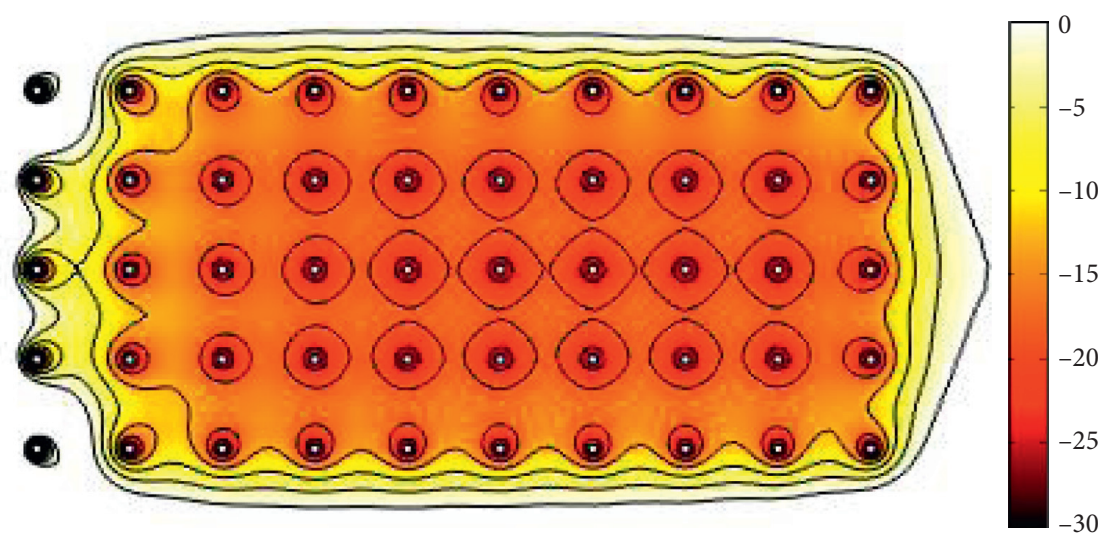

(e)

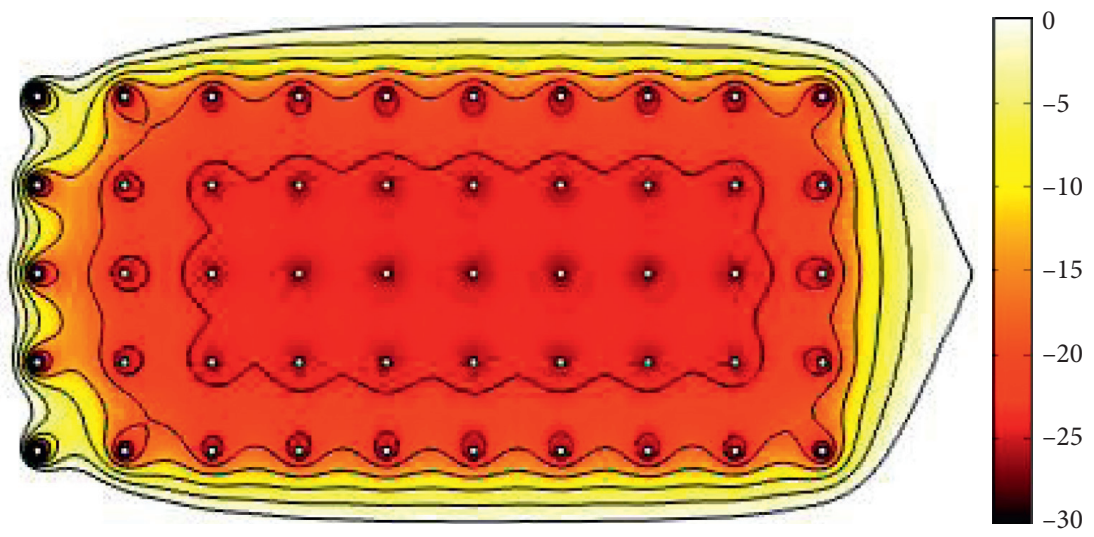

(f)

Figure 5: Temperature field distribution of 10 rows of freezing pipe (unit: ${ }^{\circ} \mathrm{C}$ ). (a) $t=5 \mathrm{~d}$. (b) $t=8 \mathrm{~d}$. (c) $t=10 \mathrm{~d}$. (d) $t=15 \mathrm{~d}$. (e) $t=25 \mathrm{~d}$. (f) $t=40 \mathrm{~d}$.

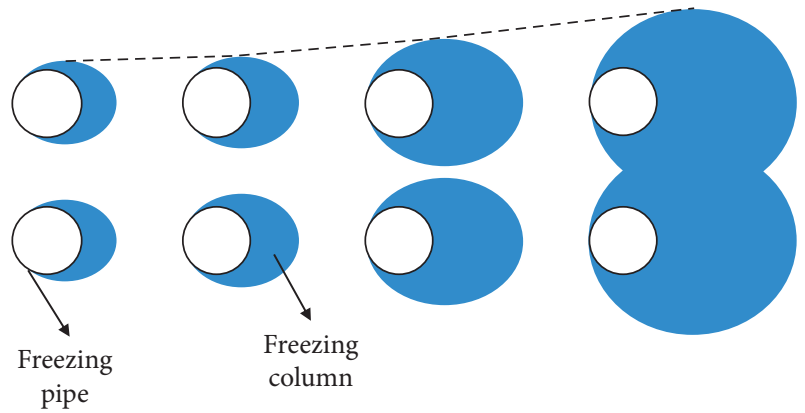

FIGURE 6: Cooling capacity spreading of multirow freezing pipes under seepage condition.

each other; as a result, the freezing columns of rear pipes intersect, as shown in Figure 5(c). After 15 days, the overall multirow pipes freezing shows a trend of developing from back water surface to front water surface, until all the freezing columns intersect. The reason is that, after the downstream freezing columns intersect, the seepage field in the freezing area is affected. As shown in Figure 7, a certain range of deceleration zones appeared upstream of the frozen area, thereby promoting the development of freezing in the corresponding area.
After all freezing columns are connected together, the temperature of the frozen core area gradually decreases. During this process, it was found that the first row of freezing pipes was relatively lagging in the freezing development, and the process of connecting it to the frozen area has greatly extended the overall time of the entire group. In the actual project, partial encryption of the first row of freezing pipes can speed up the overall freezing process.

As shown in Figure 5(f), after the temperature field stabilizes, the isotherm changes sharply on the front water surface and is relatively flat on back water surface, and the lowest temperature in the core freezing area is around $-25^{\circ} \mathrm{C}$. The zero-temperature line surrounds the entire area and forms a bulge on the back water surface.

Under the seepage condition, the cooling capacity of the upstream freezing pipes will follow the flow downstream, reducing the ambient temperature around the downstream freezing pipes, thereby promoting the freezing of the downstream part. When the row number is sufficient, the downstream freezing column will first connect, which will reduce the seepage velocity through upstream freezing pipes and promote the development of its freezing, and eventually the group shows the 


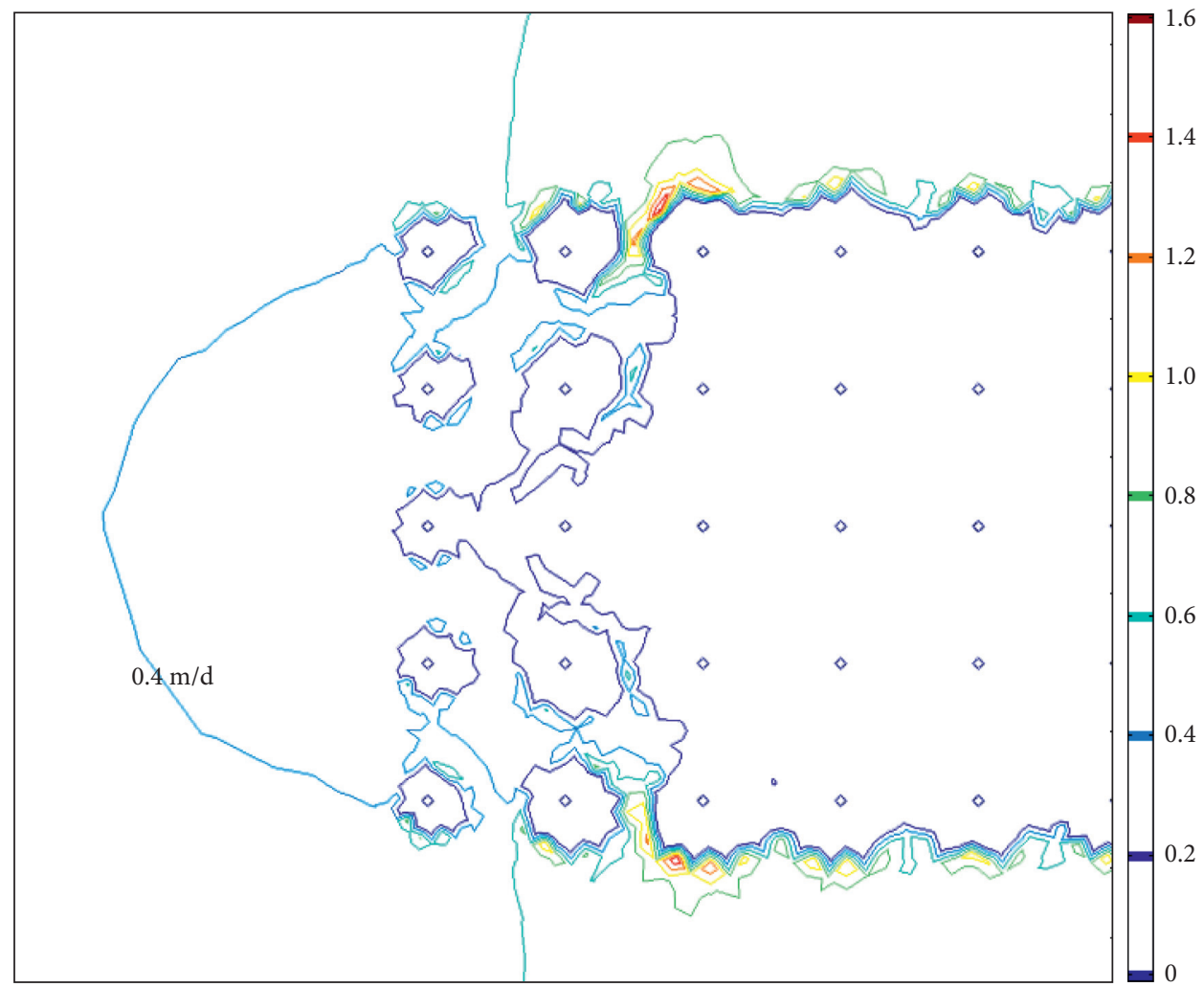

Figure 7: Velocity field of multirow freezing pipes $(t=15 \mathrm{~d}, v=0.5 \mathrm{~m} / \mathrm{d})$.

phenomenon of gradual development from back water surface to front water surface.

In summary, the group-effect refers to the cooling effect of different freezing pipes influencing each other when multirow freezing pipes are working together. Under the condition of still water, the group-effect expands the frozen area, while it shows the gradual development of freezing from back water surface to front water surface under seepage condition. The superposition of the temperature field promotes the change of the freezing effect. The development of the overall freezing is not a simple copy of the freezing process of multiple single pipes but as a whole shows a phenomenon different from the freezing of single pipe.

\section{Basin-Shaped Freezing Method}

Physical model test and numerical simulation were used to study the freezing process and temperature expansion of BFM. Usually, model test can only satisfy the similar relationship on the main conditions, follow the principle of highlighting the core elements of simulation, and eliminate the boundary effect to the greatest extent. The geometric similarity ratio selected is $C_{l}=1: 10$. According to $\pi$ theory, the similarity ratio of parameters involved in the analysis process is shown in Table 2.

Among them, $l$ represents the geometric size including the length of the freezing pipe and the spacing of the freezing pipes; $T$ is temperature; $t$ is time; $v$ is the seepage velocity. In addition, the angle $p$ represents the prototype and $m$ represents the model.
TABle 2: Parameters similarity ratio in the model test.

\begin{tabular}{lccc}
\hline Parameter & Symbol & Deduction & Value \\
\hline Geometry & $C_{l}$ & $C_{l}=l_{m} / l_{p}$ & $1: 10$ \\
Temperature & $C_{T}$ & $C_{T}=T_{m} / T_{p}$ & $1: 1$ \\
Time & $C_{t}$ & $C_{t}=t_{m} / t_{p}=\left(l_{m} / l_{p}\right)^{2}$ & $1: 100$ \\
Seepage velocity & $C_{v}$ & $C_{v}=v_{m} / v_{p}=l_{m} t_{p} / l_{p} t_{m}$ & $10: 1$ \\
\hline
\end{tabular}

4.1. Physical Model. The physical model test uses the seepage freezing model test platform for operation. The platform is composed of model test box, water tank, brine tank, refrigeration compressor, and cooling towel. Among them, the water tank provides a circulating water system to simulate groundwater seepage condition; in the brine tank, the brine is circulated in the freezing pipe after cooling by the compressor. The test box is the main area for constructing strata, arranging freezing pipes, and conducting physical model tests. The model box here is $10 \mathrm{~m}$ long, $3 \mathrm{~m}$ wide, and $2.5 \mathrm{~m}$ high, as shown in Figure 8.

The layout of the stratum in the model box is shown in Figure 9. From top to bottom, there are the silty sand layer, the upper sealing water layer, the sandy gravel layer, the lower sealing water layer, and the sandy gravel layer. Water enters from one side of the tank and flows out from the other side to simulate groundwater seepage. The effective flow section height of this model is $1.5 \mathrm{~m}$.

The layout of the freezing pipes is shown in Figure 10. According to the similar relationship, the diameter of the freezing pipe is $160 \mathrm{~mm}$. The model includes 90 freezing 


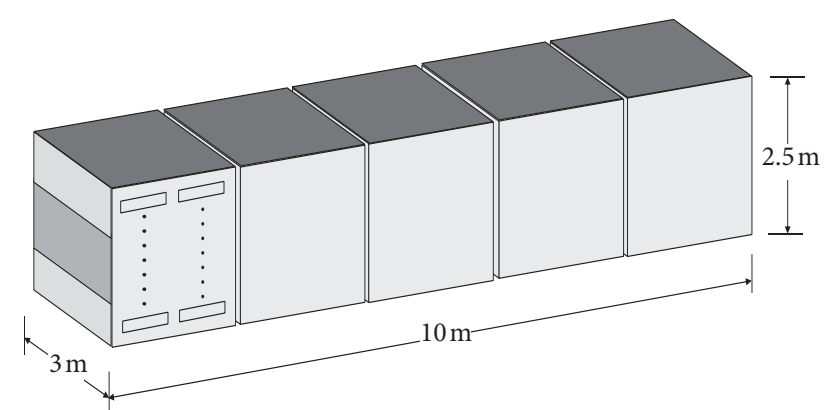

Figure 8: Model test chamber.

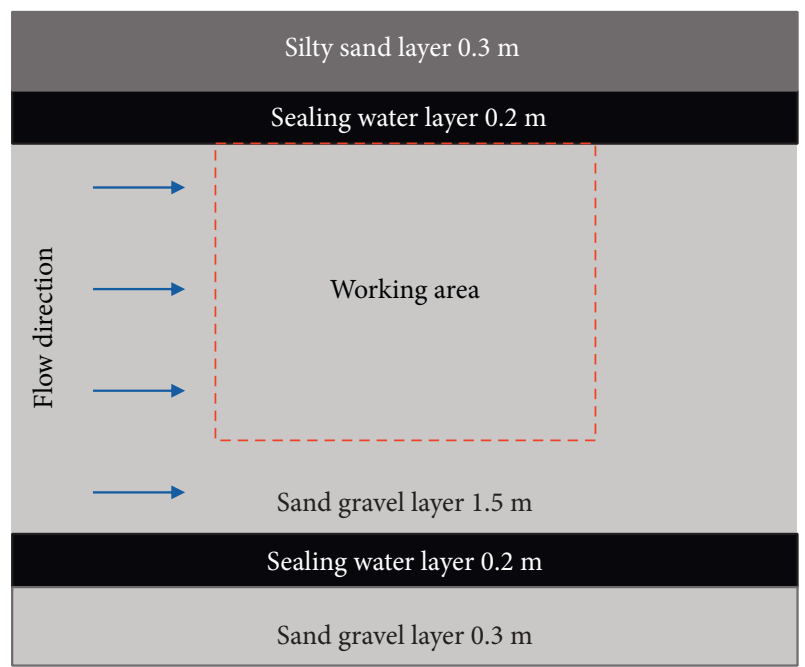

Figure 9: Vertical distribution of strata.

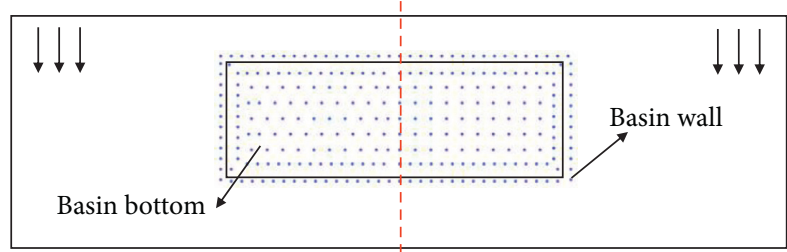

FIGURE 10: Distribution of freezing pipes.

pipes on basin wall and 180 freezing pipes on basin bottom, for a total of 270 freezing pipes. Among them, the spacing between basin wall freezing pipes is $0.135 \mathrm{~m}$, the freezing pipes inside the basin bottom are evenly arranged, the spacing is $0.2 \mathrm{~m}$, and the encryption freezing pipes are arranged at corner points. Basin bottom freezing pipes are arranged in a regular array on the right side of the axis of symmetry and quincunx arrangement on the left side. In the subsequent analysis, only the right side is analyzed.

The freezing pipe at basin bottom adopts the method of partial freezing. Its effective freezing length is $0.5 \mathrm{~m}$, and that of the basin wall is $1.3 \mathrm{~m}$. Figure 11 is the physical model test box before capping, from which you can see the arrangement of freezing tubes.

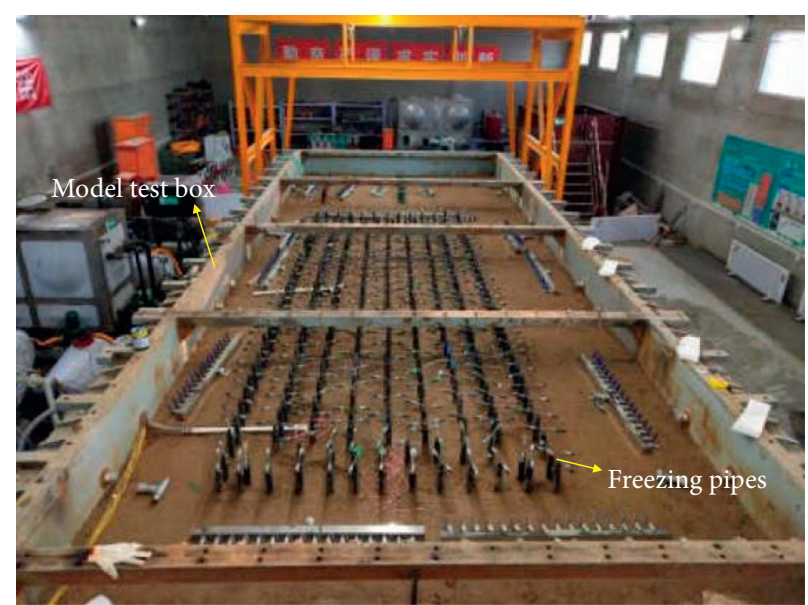

Figure 11: Physical model test of freezing pipes.

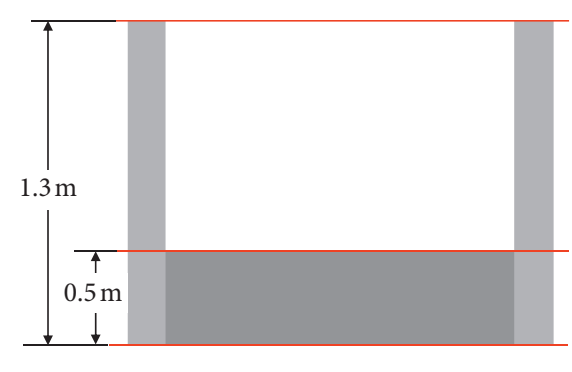

1: upper end surface of the basin wall

2: upper end surface of the basin bottom

3: lower end surface of the basin bottom

FIGURE 12: Key cross sections in the basin-shaped freezing model.

4.2. Freezing Sequence under Still Water. The physical model test was mainly carried out two times under the conditions of still water and seepage velocity of $5 \mathrm{~m} / \mathrm{d}$. According to the similar theory, those two tests correspond to the conditions of still water and seepage velocity of $0.5 \mathrm{~m} / \mathrm{d}$ in actual engineering. The physical model test can only monitor a limited number of temperature measurement points, while the numerical simulation can describe the whole temperature field more intuitively and completely. In the following, the physical model test mainly recorded 3 key cross sections of the structure, and they are shown in Figure 12.

The physical model test records the temperature at different positions during the test, while, in numerical simulation, the freezing range is depicted on the same section with a red-dashed line according to the test results, as shown in Figure 13. Under still water, all the freezing columns are frozen and connected within 15 hours. The analysis selected three key time points of 5 hours, 10 hours, and 15 hours. According to the similar theory, they represent about 20 days, 40 days, and 60 days in actual engineering. As can be seen from the figure, the freezing range of the cross sections determined according to the numerical simulation results is basically consistent with the temperature of the measurement points in physical model test, which verifies the validity of the simulation.

After freezing for 20 days, the corner freezing pipes at the lower end and upper end surfaces of the basin bottom were 


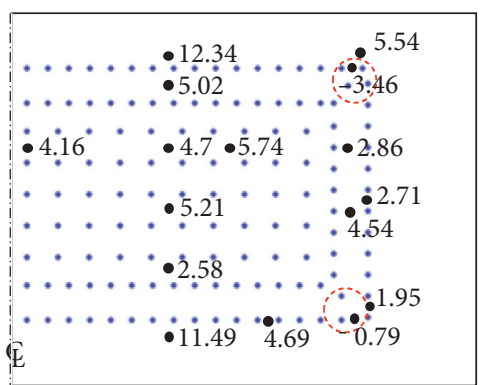

(1) Key C-S $1(t=20 \mathrm{~d})$

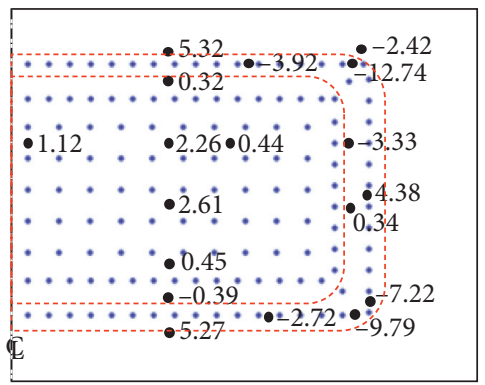

(4) Key C-S $1(t=40 \mathrm{~d})$

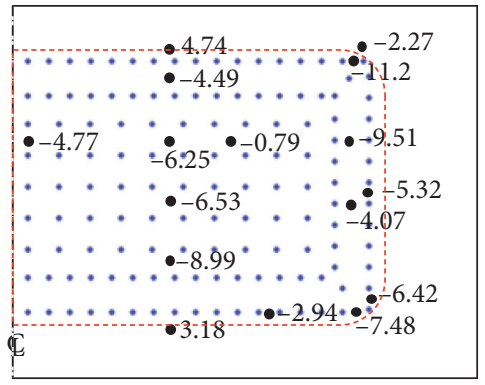

(7) Key C-S $1(t=60 \mathrm{~d})$

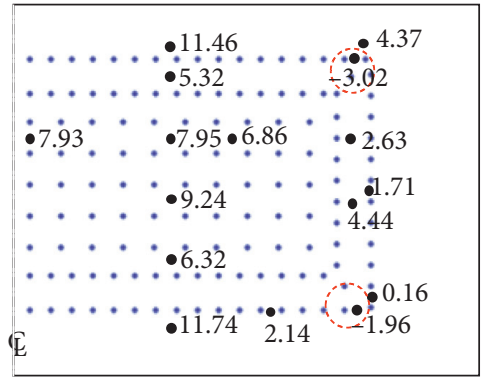

(2) Key C-S $2(t=20 \mathrm{~d})$

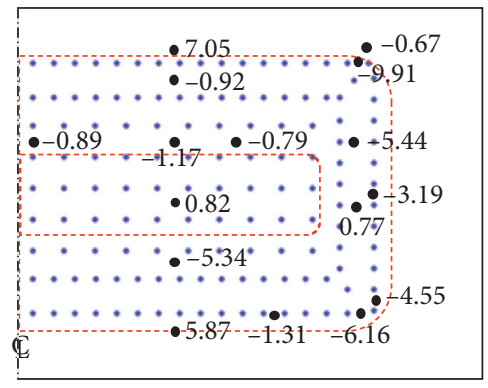

(5) Key C-S $2(t=40 \mathrm{~d})$

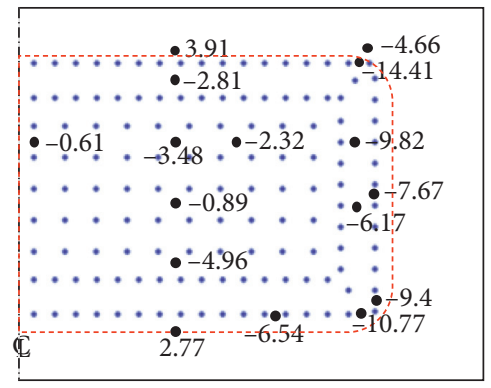

(8) Key C-S $2(t=60 \mathrm{~d})$

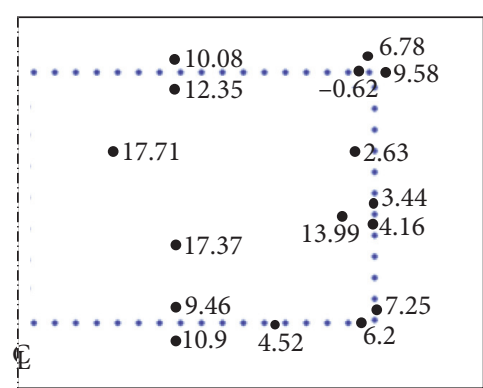

(3) Key C-S $3(t=20 \mathrm{~d})$

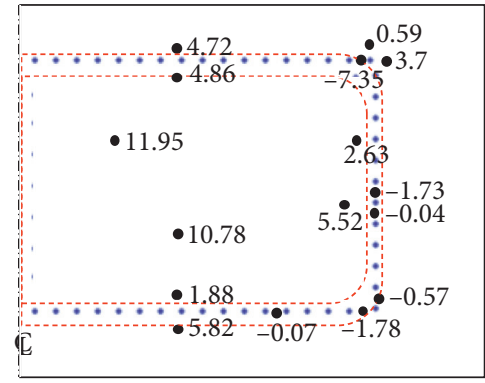

(6) Key C-S $3(t=40 \mathrm{~d})$

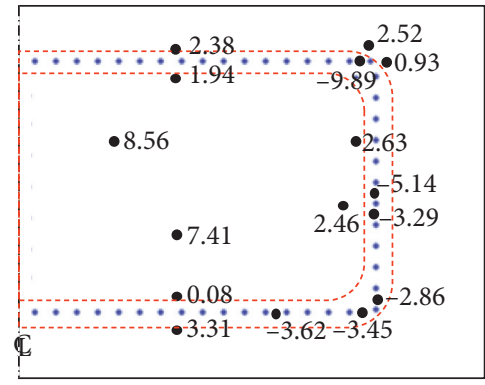

(9) Key C-S $3(t=60 \mathrm{~d})$

FIgURE 13: Measuring points temperature and freezing range in numerical model under still water.

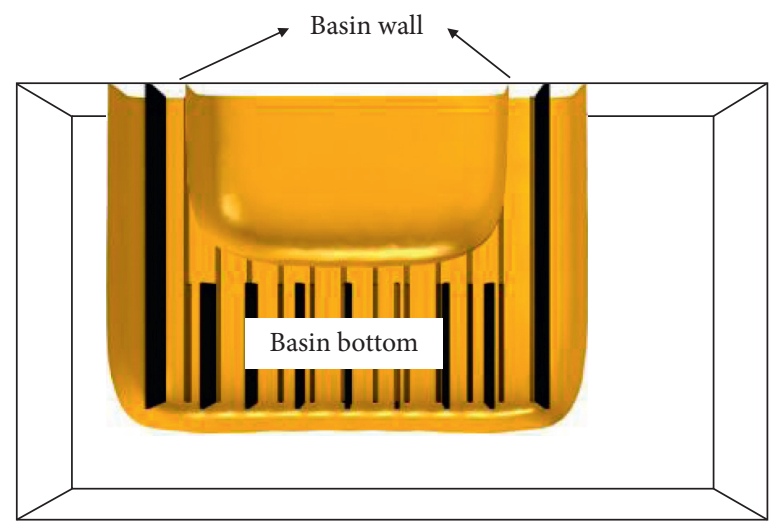

Figure 14: Freezing basin structure under still water.

partially frozen and connected, because freezing pipes are relatively dense and the spacing is smaller, which is promoting the development of freezing; at the same time, there is no freezing phenomenon on the upper end surface of the basin wall. After freezing for 40 days, at the lower end of the basin bottom, relying on the area where the corners have connected, the freezing gradually develops along the edge of freezing pipes and the densely arranged area connected at this time; on the upper end of the basin bottom, the freezing develops from the surroundings to the inside, and the reason why the development is faster than the lower end of the basin bottom is because the lower end surface is more conducive to 


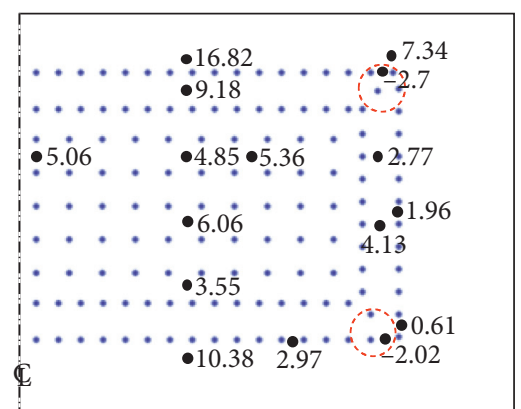

(1) Key C-S $1(t=20 \mathrm{~d})$

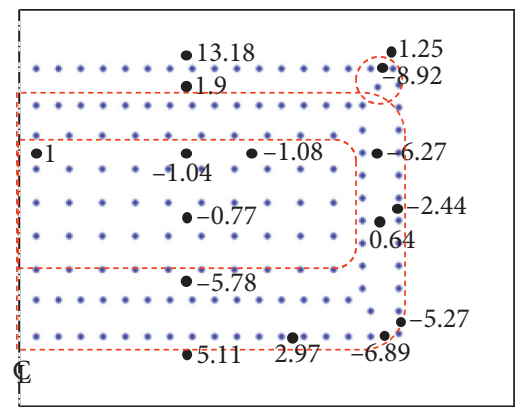

(4) Key C-S $1(t=40 \mathrm{~d})$

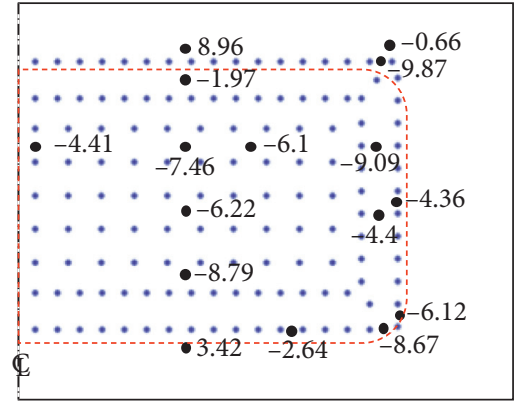

(7) Key C-S $1(t=60 \mathrm{~d})$

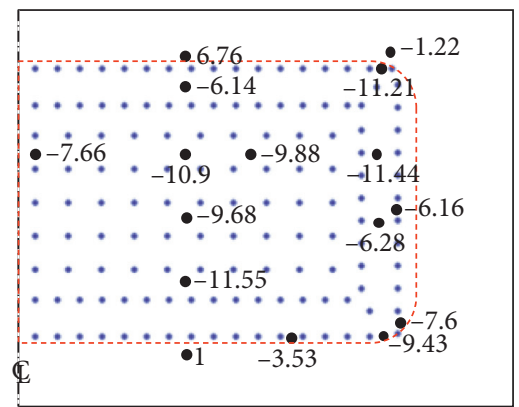

(10) Key C-S $1(t=80 \mathrm{~d})$

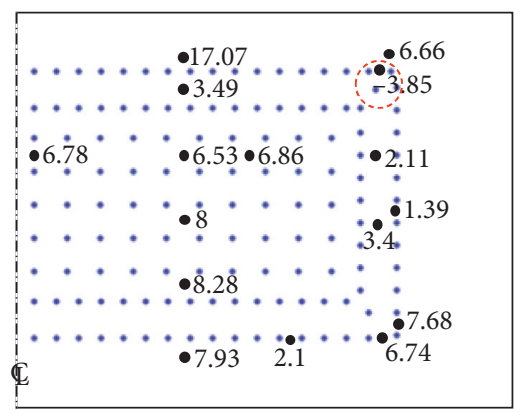

(2) Key C-S $2(t=20 \mathrm{~d})$

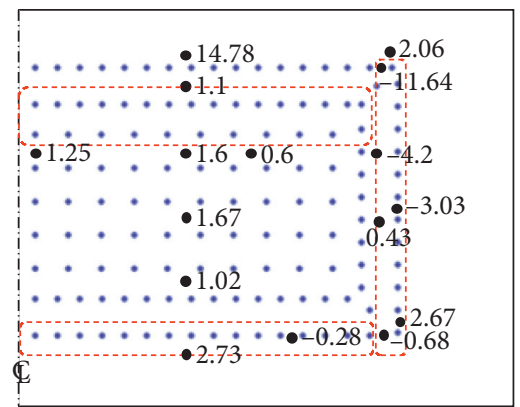

(5) Key C-S $2(t=40 \mathrm{~d})$

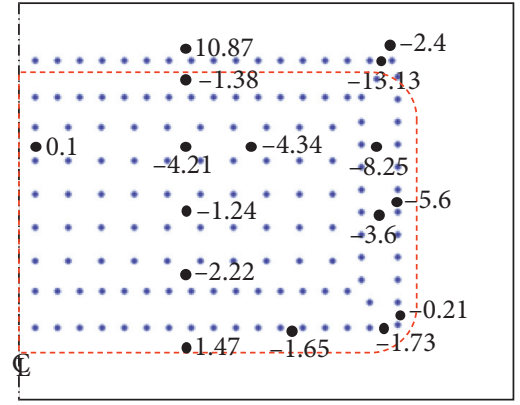

(8) Key C-S $2(t=60 \mathrm{~d})$

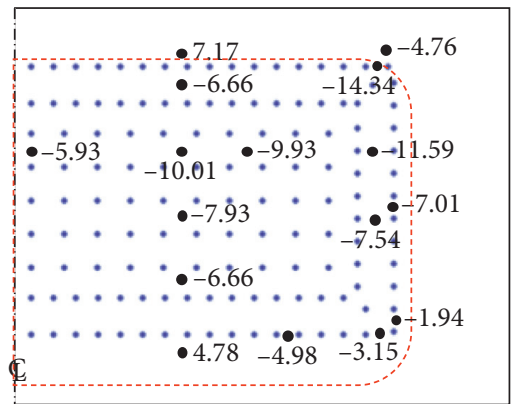

(11) Key C-S $2(t=80 \mathrm{~d})$

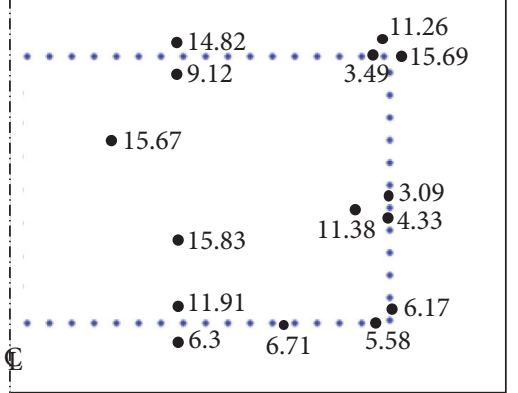

(3) Key C-S $3(t=20 \mathrm{~d})$

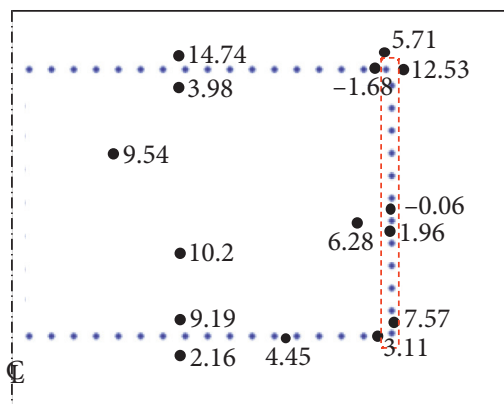

(6) Key C-S $3(t=40 \mathrm{~d})$

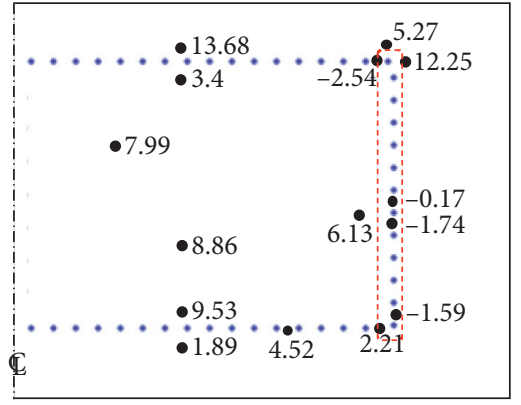

(9) Key C-S $3(t=60 \mathrm{~d})$

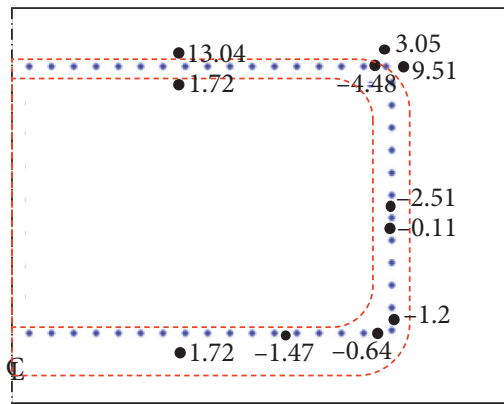

(12) Key C-S $3(t=80 \mathrm{~d})$

FIGURE 15: Measuring points temperature and freezing range in numerical model under seepage condition.

heat exchange; on the upper end of the basin wall, most of the freezing pipes connected and temperature was around $-1^{\circ} \mathrm{C}$. After freezing for 60 days, the measuring points of all the areas on the 3 sections have fallen below $0^{\circ} \mathrm{C}$, which can be considered as the formation of a basin-shaped freezing structure. The numerical simulation results are shown in Figure 14, from which we can see that the basin structure with certain thickness is finally formed under the condition of still water.
According to the comparison results, the freezing development is closely related to the spacing of the freezing pipes. Space at basin wall is small, freezing will occur first, the temperature will gradually decrease with the subsequent development, and the freezing range will gradually expand. When the freezing ranges at the upper and lower end surfaces of the basin bottom are connected, it can be considered that the basin bottom is formed. During the test, the lower end of the basin bottom is in full contact with 


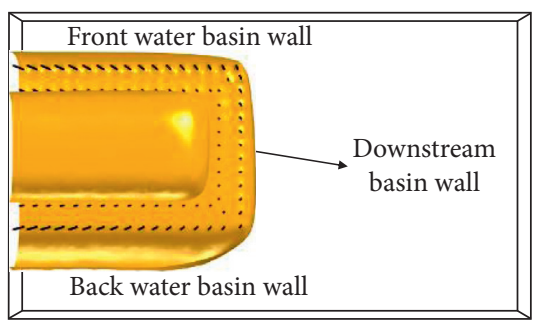

(a)

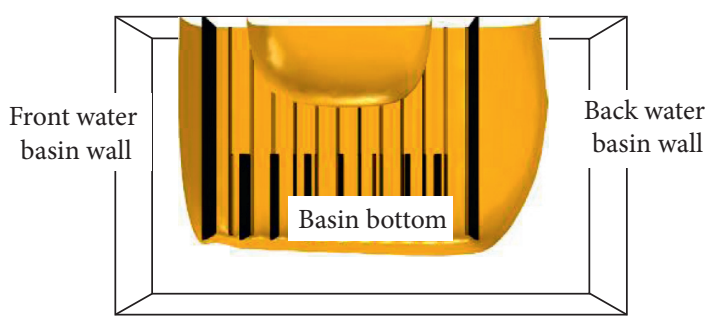

(b)

FIgURE 16: Freezing basin structure under seepage condition. (a) Vertical view. (b) Side view.

groundwater, which is conducive to the diffusion of cooling, and the freezing is slower than that of the upper end of the basin bottom. Therefore, under still water conditions, the basin wall will be formed before the basin bottom.

4.3. Freezing Sequence under Seepage Condition. The freezing process of the key section under the seepage condition $(0.5 \mathrm{~m} / \mathrm{d})$ is shown in Figure 15. Four time points of 5 hours, 10 hours, 15 hours, and 20 hours were selected in the physical model test process. According to the similar theory, they, respectively, represent 20 days, 40 days, 60 days, and 80 days.

After freezing for 20 days, the upper and lower end surfaces of the basin bottom were connected only at the corners, similar to those under still water conditions; the upper end surface of the basin wall has not been frozen. After freezing for 40 days, except for the first row on front water surface, all the freezing pipes at the lower end of basin bottom connected and showed the trend of developing from the surrounding to the central part; on the upper end of basin bottom, only local connection occurred around the downstream basin wall, and the freezing was slower than that of the lower end of the basin bottom; the downstream basin wall on the upper end of the basin wall connected first. After freezing for 60 days, only the first row freezing pipe on the front water surface did not connect on the lower and upper end surfaces of the basin bottom; after downstream basin wall freezing on the upper end surface of basin wall, it gradually extends to adjacent basin wall. After freezing for 80 days, all the measurement points on these 3 cross sections fell below $0^{\circ} \mathrm{C}$, and it can be considered that a basin-shaped freezing structure has been formed. The numerical simulation results are shown in Figure 16.

Therefore, under seepage condition, the order of freezing connection at different positions is as follows: downstream basin wall, basin bottom, back water basin wall, and front water basin wall. From the comparison results, it can be seen that the freezing range of the numerical simulation is basically consistent with the temperature measurement points of the physical model test. A few unfrozen measurement points are also near $0^{\circ} \mathrm{C}$, and the error is very small. The established numerical model can effectively reflect the development process of basin freezing and predict the development of temperature field effectively. After the model test, the final basin-shaped structure (one side) is shown in Figure 17.

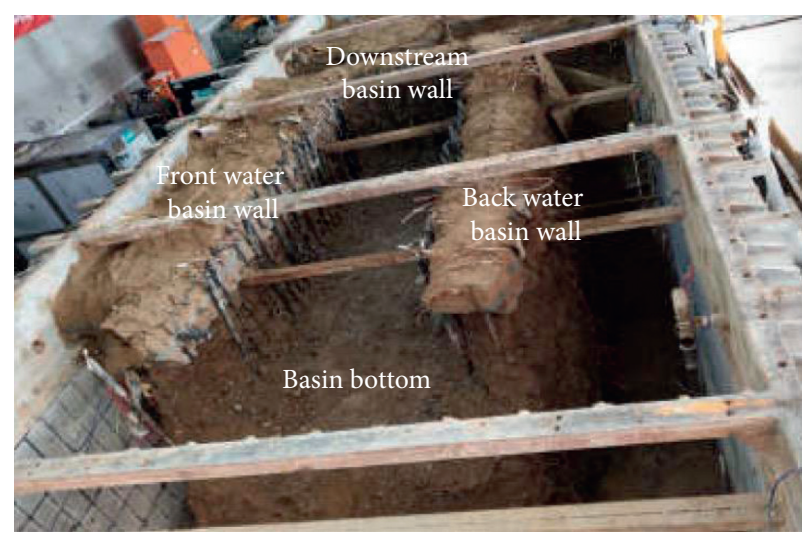

FIGURE 17: Basin-shaped structure in the model test (one side).

\section{Conclusion}

In this paper, based on the typical water-rich sandy gravel strata in Beijing, in order to solve the difficulty of large-scale underground engineering water proofing in urban sensitive areas, the formation and development of freezing body were analyzed when multirow freezing pipes were working together, and the group effect exhibited was also revealed. On this basis, the basin-shaped freezing method (BFM) is put forward as an application of AGF used in underground engineering; temperature field expansion of this method is studied, especially freezing sequence of different positions of basin structure under different seepage condition. The main conclusions are as follows:

(1) The group effect refers to the cooling effect of different freezing pipes influencing each other during freezing process. Under the condition of still water, the group effect expands the freezing area, and it shows the gradual development of freezing from back water surface to front water surface under seepage condition.

(2) BFM can effectively play the role of water proofing, and although different parts of basin structure show different frozen order under different conditions, both basin wall and basin bottom can form an effective thickness during the freezing process.

(3) Under still water conditions, the basin wall will be formed before the basin bottom; under seepage condition, the order of freezing connection of BFM structure is 
as follows: downstream basin wall, basin bottom, back water basin wall, and front water basin wall.

\section{Data Availability}

The data used to support the findings of the study are included in the article.

\section{Conflicts of Interest}

The authors declare that they have no conflicts of interest.

\section{Acknowledgments}

This research was supported by the Beijing Municipal Commission of Science and Technology Foundation (Z161100001116088).

\section{References}

[1] Z. Yu, H. Huang, R. Wang et al., "Application of the artificially ground freezing method to Shanghai metro engineering," Journal of Glaciology and Geocryology, vol. 27, no. 4, pp. 550-556, 2005.

[2] X. Chen and C. Yang, "Horizontal freezing construction technology of Beijing and Shanghai metro," Chinese Journal of Rock Mechanics and Engineering, vol. 18, pp. 978-981, 1999.

[3] J. Qiao, L. Tao, and S. Mo, "Simulation study on deformation characteristics of ground surface in horizontal freezing construction of metro tunnel," Chinese Journal of Rock Mechanics and Engineering, vol. 23, no. 15, pp. 2643-2646, 2004.

[4] L. Wang and Z. Zhu, "Extra-long horizontal frozen technique used in the construction of one Guangzhou metro tunnel through fractured zone," Modern Tunnel Technology, vol. S2, pp. 440-444, 2004.

[5] P. Yang and A. Pi, "Study on the effects of large groundwater flow velocity on the formation of frozen wall," Chinese Journal of Geotechnical Engineering, vol. 23, no. 2, pp. 167-171, 2001.

[6] X. Zhou, "Stressing of freeze pipe in the deformed section of ice wall," Journal of China Coal Society, vol. 1, pp. 30-34, 1996.

[7] X. Zhou, "Model test and coupled field finite element simulation study on the formation law of artificial frozen wall under the action of water seepage," Doctor Degree tesis, Beijing Jiaotong University, Beijing, China, 2004.

[8] J. Gao, M. Feng, and W. Yang, "Research on distribution law of frozen temperature field of fractured rock mass with groundwater seepage," Journal of Mining \& Safety Engineering, vol. 30, no. 1, pp. 68-73, 2013.

[9] F. Li, H. Ding, and X. Zhang, "Model test research of formation law of double-row-pipe freezing wall in water rich sand layer under seepage," Chinese Journal of Rock Mechanics and Engineering, vol. 38, no. 2, pp. 386-395, 2019.

[10] J. Liu, Q. Liu, D. Zhou, and X. Zhu, "Influence of groundwater transverse horizontal flow velocity on the formation of artificial horizontal freezing wall," Journal of Basic Science and Engineering, vol. 25, no. 2, pp. 258-265, 2017.

[11] Ministry of Finance, "Measures for the pilot implementation of water resources tax reform," Ministry of Finance, State Administration of Taxation and Ministry of Water Resources, Ministry of Finance People's Republic of China, Beijing, China, 2017.

[12] K. M. Neaupane and T. Yamabe, "A fully coupled thermohydro-mechanical nonlinear model for a frozen medium," Computers and Geotechnics, vol. 28, no. 8, pp. 613-637, 2001. 